\title{
The effect of selected inhibitors on the characteristics of wood dust explosion
}

\author{
Lukasz Zubek ${ }^{1, *}$, Mirosław Sobolewski ${ }^{1}$ \\ ${ }^{1}$ The Main School of Fire Services, Faculty of Fire Safety Engineering, 52/54 Slowackiego St., \\ 01-629 Warsaw, Poland
}

\begin{abstract}
The mass concentration of four inhibitors which is required to suppress pine dust explosion were measured in laboratory-scale system. Measurements were conducted using four commercially available additives commonly used to decrease the fire and explosion hazards, three extinguishing powders: BC FOREX C, ABC Favorit X90, BC 101K and rock dust powder consisting calcium carbonate $\mathrm{CaCO}_{3}$ and magnesium carbonate $\mathrm{MgCO}_{3}$. The inhibition effect was investigated by measuring explosion pressure of various dust/powder mixtures using a $20 \mathrm{dm}^{3}$ sphere by PN-EN 14034. On the basis of pressure-time curves the derivatives of pressure with respect to time $(\mathrm{dp} / \mathrm{dt})$, maximum explosion pressure $\mathrm{p}_{\max }$ and maximum rate of explosion pressure rise $(\mathrm{dp} / \mathrm{dt})_{\max }$ were determined. It was found that inhibiting dust explosions with additives of various dry powders is a very effective way to decrease explosion effects. The experimental results have also shown that inhibiting effectiveness is strictly related to chemical composition of the powder. The order of effectiveness was monoammonium phosphate, sodium bicarbonate, potassium bicarbonate and rock dust.
\end{abstract}

\section{Introduction}

Over $70 \%$ of dust produced and used in industrial processes has flammable properties. Some of them are processed in a particulate form, others although they are generally not in the form of dust, they contain finely divided particles capable of forming a mixture with air. Particulate solid particles of organic origin, including waste wood, are used, for example, as fuel in pulverized boilers to produce energy necessary for the proper conduct of many industrial processes.

The collection of factors necessary for the occurrence of a dust explosion includes five elements and is commonly referred to as the explosion pentagon. These include: combustible dust, ignition source, oxidant, limited space and mixing. The mixing process is necessary to create a dust-air mixture. The limitation of space favors the achievement of appropriate concentrations and favors the dynamics of the explosion [1]. Figure 1 shows the schematic view of the components of the explosion pentagon.

The dynamics of the dust explosion and its consequences are determined by many factors. The set of these factors is classified according to four criteria, which include: dust

\footnotetext{
* Corresponding author: lzubek@sgsp.edu.pl
} 
properties, explosion space characteristics, characteristics of the explosion initiator and explosive properties of the mixture. The explosive properties of the mixture can be modified by introducing inhibitory additives. The presence of combustion inhibitors directly affects the process and dynamics of the explosion of combustible dust-air mixtures. By acting directly on the physical and chemical way, inhibitors modify the parameters and course of individual explosion characteristics. The presence of inhibiting additives in dust clouds results in a reduction of the maximum explosion pressure $\left(\mathrm{p}_{\max }\right)$ and the maximum rate of explosion pressure rise $\left(\mathrm{dp} / \mathrm{dt}_{\max }\right)$ and an increase in both the lower explosion limit (LEL) and the minimum ignition energy of the dust cloud (MIE). The effectiveness of additives with a different chemical composition is diversified, which indicates a correlation between the inhibitor's chemical composition and its effectiveness [2, 3].

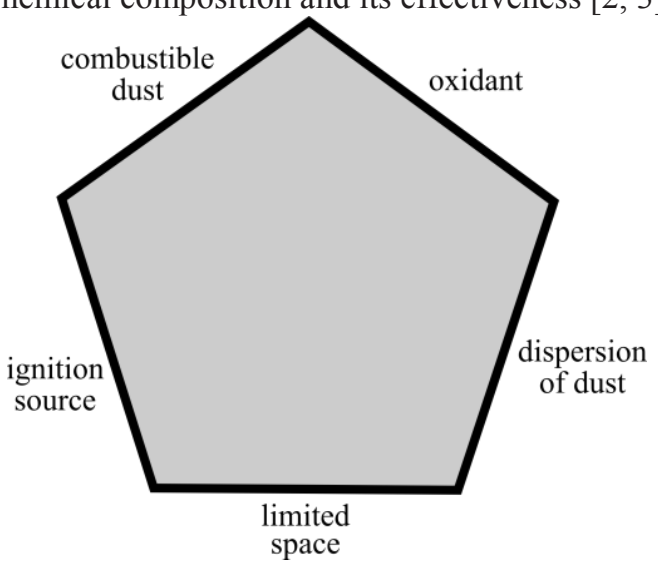

Fig. 1. Explosion pentagon.

The article presents the results of the research, which aimed at comparing the influence of four selected inhibitors on the values of selected characteristics of explosiveness of pine wood dust and determination of inertising concentrations. Three extinguishing powders and stone dust widely used in fire protection were used as inhibitors.

\section{Materials and methods}

\subsection{Description of materials for testing}

The tests were carried out for the dust formed as a result of pine wood scraping. The timber treatment of this type of wood is very common due to the wide spectrum of its practical applications. Pine wood has been used in the production of furniture, windows, doors, floors and paper. The main reason for choosing the type of combustible material were the hazards posed by pine dust in the wood processing industry. Due to its explosive properties and a significant increase in pressure, up to 6 bar, it is a significant threat to the safety of both employees and industrial processes.

Extinguishing powders of different chemical composition were used as inhibitors in the research. Both the extinguishing powders and (tested for comparison) the stone dust have a similar grain composition and are protected against moisture. The main purpose of introducing the $\mathrm{BC} 101 \mathrm{~K}$ extinguishing powder for testing was to compare the inhibitors properties of potassium bicarbonate and sodium bicarbonate in low concentrations. For this reason, the approximate value of the inerting concentration was determined for the powder $\mathrm{BC} 101 \mathrm{~K}$. The chemical composition and particle size distribution of powders have a significant impact on the mechanisms of combustion and explosion processes. Following 
the criteria set out above, four inhibitors were selected, the characteristics of which are presented in Table 1. Each characteristic were prepared on the basis of manufacturer brochures.

Table 1. Characteristics of inhibitors used in research.

\begin{tabular}{|c|c|c|c|c|c|c|c|}
\hline No. & $\begin{array}{c}\text { Manufacture } \\
\mathbf{r}\end{array}$ & $\begin{array}{l}\text { Trade } \\
\text { name }\end{array}$ & $\begin{array}{c}\text { Main } \\
\text { ingredient } \\
\text { [wt \%] }\end{array}$ & $\begin{array}{l}\text { Hydropho } \\
\text { bic } \\
\text { additive }\end{array}$ & $\begin{array}{l}\text { Density } \\
{\left[\mathrm{g} / \mathrm{cm}^{3}\right]}\end{array}$ & $\begin{array}{c}\text { Bulk } \\
\text { density } \\
{\left[\mathrm{g} / \mathrm{cm}^{3}\right]}\end{array}$ & $\begin{array}{c}\text { Size } \\
\text { distributio } \\
n\end{array}$ \\
\hline 1. & $\begin{array}{c}\text { Suzhou } \\
\text { Wuyue } \\
\text { Synthetic } \\
\text { Chemical } \\
\text { Factory }\end{array}$ & FOREX C & $\begin{array}{c}\text { sodium } \\
\text { bicarbonate } \\
\mathrm{NaHCO}_{3} \\
(>93 \%)\end{array}$ & siloxanes & $2,1-2,2$ & $1,1-1,15$ & - \\
\hline \multirow{4}{*}{2.} & \multirow{4}{*}{$\begin{array}{c}\text { Ansul } \\
\text { incorporated }\end{array}$} & \multirow{4}{*}{$\begin{array}{c}\text { ABC } \\
\text { Favorit } \\
\text { X90 }\end{array}$} & \multirow{4}{*}{$\begin{array}{c}\text { monoammoni } \\
\text { um phosphate } \\
\mathrm{NH}_{4} \mathrm{H}_{2} \mathrm{PO}_{4} \\
(90 \pm 3 \%)\end{array}$} & \multirow{4}{*}{ siloxanes } & \multirow{4}{*}{1,9} & \multirow{4}{*}{$0,90 \pm 0,07$} & $\begin{array}{c}>40 \mu \mathrm{m} \\
35,0 \% \pm \\
8 \%\end{array}$ \\
\hline & & & & & & & $\begin{array}{c}>63 \mu \mathrm{m} \\
21,5 \% \pm \\
8 \%\end{array}$ \\
\hline & & & & & & & $\begin{array}{c}>125 \mu \mathrm{m} \\
8,0 \% \pm 5 \%\end{array}$ \\
\hline & & & & & & & $\begin{array}{c}>250 \mu \mathrm{m} \\
0 \%\end{array}$ \\
\hline \multirow{3}{*}{3.} & \multirow{3}{*}{$\begin{array}{c}\text { Ansul } \\
\text { incorporated }\end{array}$} & \multirow{3}{*}{ BC $101 \mathrm{~K}$} & \multirow{3}{*}{$\begin{array}{c}\text { potassium } \\
\text { bicarbonate } \\
\mathrm{KHCO}_{3} \\
(93 \pm 3 \%)\end{array}$} & \multirow{3}{*}{ siloxanes } & \multirow{3}{*}{2,2} & \multirow{3}{*}{$0,90 \pm 0,07$} & $\begin{array}{c}>40 \mu \mathrm{m} \\
18,0 \% \pm \\
8 \% \\
\end{array}$ \\
\hline & & & & & & & $\begin{array}{c}>63 \mu \mathrm{m} \\
8 \% \pm 8 \%\end{array}$ \\
\hline & & & & & & & $\begin{array}{c}>125 \mu \mathrm{m} \\
2 \% \\
-2 \% /+5 \%\end{array}$ \\
\hline 4. & $\begin{array}{c}\text { Labtar sp. } \\
\text { z o.o. }\end{array}$ & $\begin{array}{c}\text { Anti- } \\
\text { explosion } \\
\text { stone dust } \\
\text { used in coal } \\
\text { mining }\end{array}$ & $\begin{array}{c}\text { calcium } \\
\text { carbonate and } \\
\text { magnesium } \\
\text { carbonate } \\
\mathrm{CaCO}_{3}, \\
\mathrm{MgCO}_{3} \\
(>92 \%) \\
\end{array}$ & stearate & - & - & $\begin{array}{c}<100 \mu \mathrm{m} \\
100 \% \\
<0,075 \mu \mathrm{m} \\
>50 \%\end{array}$ \\
\hline
\end{tabular}

The data presented in Table 1 indicate that the selected inhibitors have different chemical composition and physical properties, particularly in terms of density.

\subsection{Characteristic features of the research method}

The research aimed at determining the effect of selected inhibitors on the pine dust explosion was carried out using the test stand for testing dust explosion characteristics according to PN-EN 14034-1 in a $20 \mathrm{dm}^{3}$ sphere [4].

Prepared samples of dust and inhibitor were placed in a dust container in succession. Opening the electromagnetic valve supplying air caused the injection and atomisation of simultaneously combustible dust and inhibitor inside the explosion chamber. The ignition of the mixture of pine dust, inhibitor and air was initiated by two ignition heads with $5 \mathrm{~kJ}$ energy. The measuring module recorded pressure inside the chamber from the moment the solenoid valve was opened.

After determining LEL of pine dust, which is $30 \mathrm{~g} / \mathrm{m}^{3}$, the impact examinations of FOREX $\mathrm{C}$ for the pine dust explosion parameters at concentrations of 2xLEL, 4xLEL, $8 x L E L$ and $12 x L E L$ were carried out. Then, using the results obtained, one concentration ( $8 \mathrm{xDGW}$ corresponding to $240 \mathrm{~g} / \mathrm{m}^{3}$ ) of pine dust was selected and tests of the remaining 
inhibitors were carried out. In the second part of the experimental research there was selected the lowest possible concentration of pine dust, the explosion of which was characterized by relatively high dynamics.

In order to determine the explosion criterion of dust-inhibitor mixtures a test sample without placing the materials in the container was made. The maximum recorded overpressure produced in the chamber only by triggering the ignition initiators energy was 1.53 bar. For the needs of the research, a rounded value of overpressure of 1.6 bar was assumed as the explosion criterion. This criterion was marked in the drawings by a dotted line.

Two basic explosion characteristics were used for analytical purposes: changes in explosion pressure in time recorded by the measuring apparatus and graphs of pressuretime derivative curves calculated for each of the measurements carried out. On the basis of the curves, the change in maximum pressure values $\mathrm{p}_{\max }$ and the maximum value of the explosion pressure rate $\mathrm{dp} / \mathrm{d}_{\mathrm{tmax}}$ were determined and compared. In addition, the minimum inerting concentrations for the assumed concentrations of pine dust were determined.

\subsection{Methods of preparing samples for testing}

Before starting the tests, the moisture content in the tested dust was determined, the value of which was $6.6 \%$ by weight. In order to eliminate too large particles, the pine dust was sieved through a sieve with a mesh size of $200 \mu \mathrm{m}$. The grain distribution of the sifted dust measured using IPS-U (Infrared Particle Sizer) analyser is presented in Figure 2.

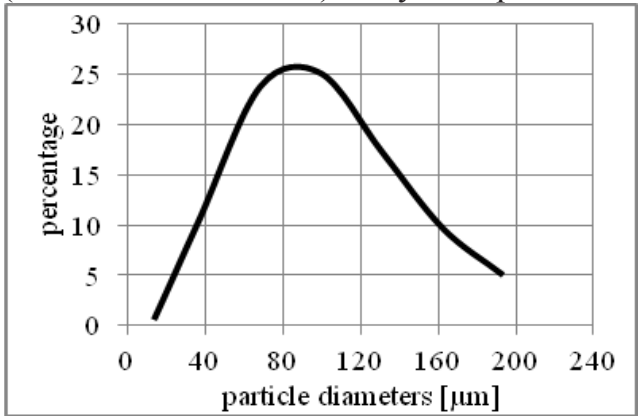

Fig. 2. Pine dust size distribution diagram.

Samples of pine dust and inhibitors prepared for testing were stored in closed plastic containers in a room with an ambient temperature of $20^{\circ} \mathrm{C}$.

Subsequent samples of dust and inhibitors were weighed on a laboratory scale. The dust and inhibitor were placed in a dust container of the test bench one by one without prior mixing. The mixing took place during the dispersion of the samples inside the explosive chamber.

\section{Results and discussion}

Figure 3 presents exemplary results of studies on the effect of additives of the FOREX C inhibitor on the characteristics of a pine dust explosion, for a dust concentration equal to $8 \mathrm{xLEL}$. The weight of pine dust for each measurement is $4.8 \mathrm{~g}$ which corresponds to a concentration of $240 \mathrm{~g} / \mathrm{m}^{3}$. 


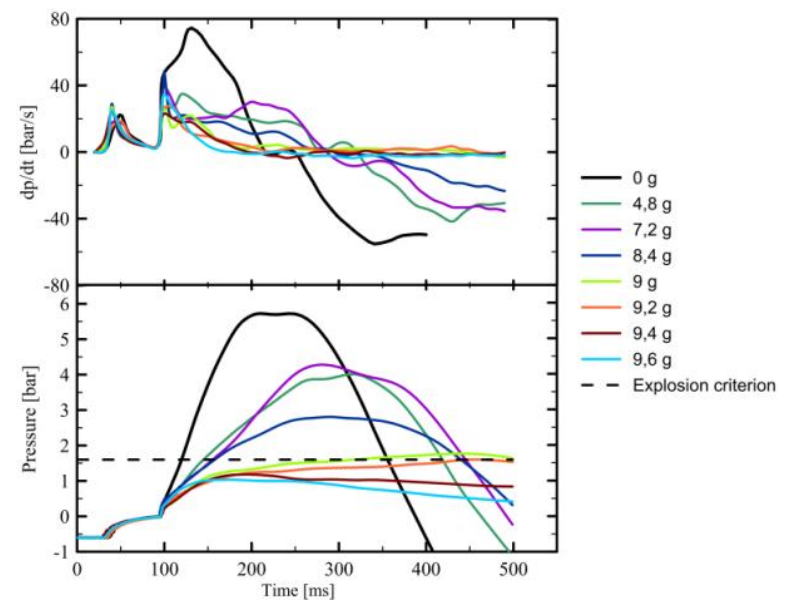

Fig. 3. The dependence of the explosion pressure and the rate of explosion pressure rise for the pine dust samples of $4.8 \mathrm{~g}$ and various FOREX C inhibitor samples.

As shown in Figure 3, the pressure-time curve of a sample containing no inhibitor additive is characterized by a dynamic course both in the growth phase and in the pressure drop. The maximum explosion pressure was 5.73 bar. Addition of $4.8 \mathrm{~g}$ of FOREX C significantly reduced the explosive properties of the tested dust. The decrease in $p_{\max }$ by 1.71 bar and $(\mathrm{dp} / \mathrm{dt})_{\max }$ by $39.6 \mathrm{bar} / \mathrm{s}$ was recorded. The $\mathrm{p}_{\max }$ values for the three consecutive measurements were varied, and were successively 4.02, 4.28 and 2.81 bar. Subsequent loadings of the inhibitor effectively limited both the dynamics of the explosion course and the $p_{\max }$ value, until the pressure curves were characterized by low dynamics, with $\mathrm{p}_{\max }$ values close to the assumed 1.6 bar explosion criterion. This criterion was adopted on the basis of measurements of pressure increase caused only by ignition heads. This pressure increase was recorded for the FOREX C sample weight of $9.2 \mathrm{~g}$, so the value of the inerting concentration can be estimated in this case at $460 \mathrm{~g} / \mathrm{m}^{3}\left(9.2 \mathrm{~g} / 20 \mathrm{dm}^{3}\right)$.

The same measurements were made for remaining concentrations of pine dust. The $\mathrm{p}_{\max }$ and $(\mathrm{dp} / \mathrm{dt})_{\max }$ parameters were obtained from the obtained explosion characteristics. Figure 4 presents the values of pine dust explosion parameters at concentrations corresponding to $2 x L E L, 4 x L E L, 8 x L E L$ and $12 x L E L$ depending on the addition of the FOREX C inhibitor.

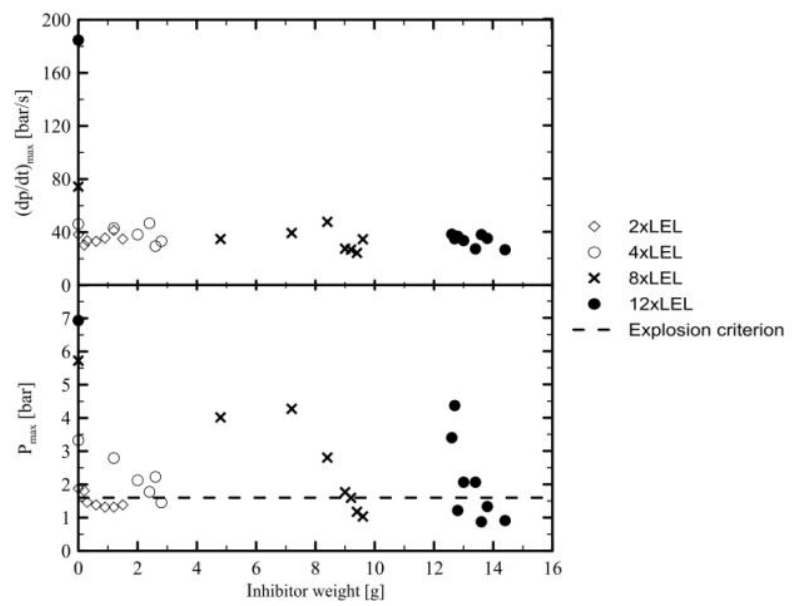

Fig. 4. $P_{\max }$ and $(\mathrm{dp} / \mathrm{dt})_{\max }$ values for different concentrations of pine dust as a function of FOREX C inhibitor additive mass. 
The data presented in Figure 4 shows that the weight of the FOREX $\mathrm{C}$ inhibitor necessary to achieve the inertial effect depends on the concentration of pine dust. For the pine dust weights corresponding to concentrations of 2xLEL, 4xLEL, 8xLEL and 12xLEL, which were respectively $1.2 \mathrm{~g}, 2.4 \mathrm{~g}, 4.8 \mathrm{~g}, 7.2 \mathrm{~g}$, the inerter inhibitor concentrations were determined to be $0.3 \mathrm{~g}, 2,8 \mathrm{~g}, 8 \mathrm{~g}, 9.2 \mathrm{~g}$ and $13.6 \mathrm{~g}$ respectively. The increase in the concentration of the inertant inhibitor is thus clearly non-linear compared to the increase in pine dust concentration.

Studies on the effect of additives of other inhibitors-extinguishing powders ABC Favorit $\mathrm{X} 90, \mathrm{BC} 101 \mathrm{~K}$ and stone dust on the explosion of pine dust were carried out for dust samples $4.8 \mathrm{~g}$ corresponding to the concentration of dust in the sphere of $240 \mathrm{~g} / \mathrm{m}^{3}$. Figure 5 shows examples of results for ABC Favorit X90 extinguishing powder, whose main ingredient is monoammonium phosphate.

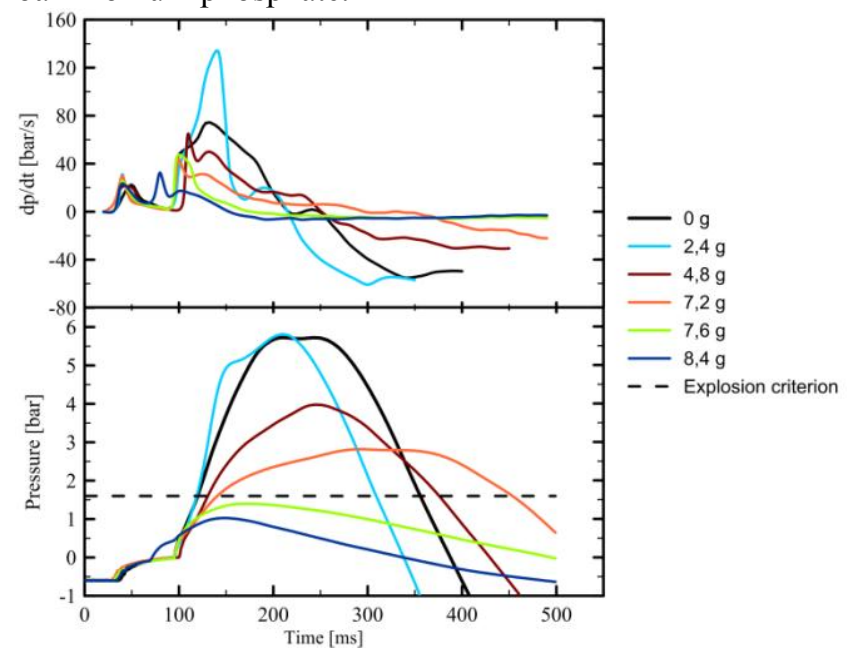

Fig. 5. The dependence of the explosion pressure and the rate of explosion pressure rise for the pine dust samples of $4.8 \mathrm{~g}$ and various samples of the ABC Favorit X90 inhibitor.

First samples of the phosphate inhibitor did not significantly affect the explosion characteristics of pine dust. For a $2.4 \mathrm{~g}$ sample of inhibitor, the maximum explosion pressure was 5.81 bar, which was a slight increase compared to the measurement without inhibitor. An increase in the dynamics of the explosion was also observed. The maximum rate of explosion pressure rise $(\mathrm{dp} / \mathrm{dt})_{\max }$ reached the value of $134.3 \mathrm{bar} / \mathrm{s}$, i.e. about 1.8 times higher than during the trial without inhibitor addition. Doubling the Favorit X90 sample led to a significant reduction in both the $\mathrm{p}_{\max }$ and the rate of pressure increase, nevertheless, the explosion continued its dynamic character, as indicated by the course of the dp/dt curve. Further increase in the concentration of extinguishing powder resulted in a gradual easing of pressure-time curves, which, as observed in previous cycles, indicates a gradual approach to the inerting concentration. These changes also illustrate $\mathrm{dp} / \mathrm{dt}$ curves, whose set of values, as the inhibitor concentration increases, is more and more limited, and the derivative values earlier stabilize at a level close to zero. The inerting sample of the Favorit X90 was determined at the level of $7.6 \mathrm{~g}$, which corresponds to the inhibitor concentration of $380 \mathrm{~g} / \mathrm{dm}^{3}$. A summary of the studies on the effect of various inhibitors on pine dust explosion is presented in Figure 6. 


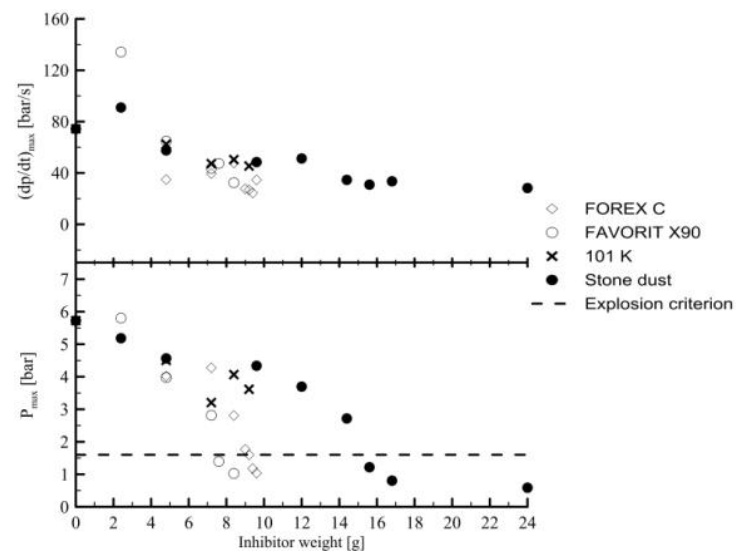

Fig. 6. $P_{\max }$ and $(d p / d t)_{\max }$ values for $4,8 \mathrm{~g}$ samples of pine dust as a function of various inhibitors additive mass.

The tested inhibitors showed different efficacy in the field of pine dust explosion. The inhibitors, which are different in chemical composition, showed a different effect both on the course of the maximal measured pressure of $p_{\max }$ and the maximum rate of explosion pressure rise $(\mathrm{dp} / \mathrm{dt})_{\max }$.

Inhibitory concentrations as well as $\mathrm{p}_{\max }$ and $(\mathrm{dp} / \mathrm{dt})_{\max }$ parameters for these concentrations are presented in Table 2.

Table 2. Inerting concentrations of tested inhibitors and changes in pine dust explosivity parameters.

\begin{tabular}{|c|c|c|c|c|c|c|}
\hline No. & Inhibitor & $\begin{array}{c}\text { Pine dust } \\
\text { concentration } \\
{\left[\mathrm{g} / \mathrm{m}^{3}\right]}\end{array}$ & $\begin{array}{c}\text { Inerting } \\
\text { sample of } \\
\text { inhibitor } \\
{[\mathrm{g}]}\end{array}$ & $\begin{array}{c}\text { Inerting } \\
\text { concentration } \\
{\left[\mathrm{g} / \mathrm{m}^{3}\right]}\end{array}$ & $\begin{array}{c}\mathrm{P}_{\max } \\
{[\mathrm{bar}]}\end{array}$ & $\begin{array}{c}(\mathrm{dp} / \mathrm{dt})_{\max } \\
{[\mathrm{bar} / \mathrm{s}]}\end{array}$ \\
\hline 1. & No inhibitor & 240 & - & - & 5,73 & 74,5 \\
\hline 2. & FOREX C & 240 & 9,2 & 460 & 1,6 & 27 \\
\hline 3. & FAVORIT X90 & 240 & 7,6 & 380 & 1,4 & 47,5 \\
\hline 4. & BC 101 K & 240 & $\approx 10$ & 500 & - & - \\
\hline 5. & Stone dust & 240 & 15,6 & 780 & 1,22 & 31 \\
\hline
\end{tabular}

The best inhibitory properties were demonstrated by ABC Favorit X90 extinguishing powder, which had an inerting concentration of $380 \mathrm{~g} / \mathrm{m}^{3}$. The FOREX C extinguishing powder, whose main component is sodium bicarbonate, showed slightly inferior inhibitory properties. The FOREX inertial concentration is approximately $81 \%$ of the Favorit X90 powder concentration. Both sodium bicarbonate and potassium bicarbonate showed similar inhibitory properties. Based on the conducted tests, it is concluded that the inertial concentration of $\mathrm{BC} 101 \mathrm{~K}$ powder is at the level of 500 $\mathrm{g} / \mathrm{m}^{3}$, which does not constitute a significant difference to FOREX. The most inferior inhibitory properties were shown by a rock dust. The inerting concentration value is more than twice than the orthophosphate concentration.

During the tests a certain scatter of recorded measurement results was observed. Often, the larger weight of the inhibitor showed much worse effectiveness in reducing the explosiveness of pine dust. Presumably, the main reason for these differences is the effect of the degree of dispersion of the inhibitor in the test chamber during the measurement. Spraying the inhibitor under the pressure of 20 bar can lead to the formation of areas of increased concentration at certain locations of the chamber, which consequently limits or improves its effectiveness. It was observed that the higher the dynamics of the dust explosion course, the more varied the results obtained, which confirms the thesis that the 
degree of dispersion of the inhibitor significantly conditioned the course of the measurement. On the basis of the conducted tests, it is difficult to determine whether the formation of a homogeneous mixture or increased concentration of the inhibitor around the sources of ignition determines the real effectiveness of the tested additive. The recorded values of the maximum measured explosion pressure $\mathrm{p}_{\max }$ below the adopted explosion criterion indicate clearly that the tested inhibitors also influence the reduction of overpressure resulting from the initiation of the ignition source. In other words, the occurrence of inhibition phenomena was observed not only in relation to the processes of combustion and heat exchange between particles of combustible dust, but also in terms of the direct interaction of the inhibitor with the ignition source.

The results of the experimental research and their analysis allow to formulate the following conclusions:

- Tested FOREX C, ABC Favorit X90 and BC $101 \mathrm{~K}$ extinguishing powders are effective inhibitors of pine dust explosion processes.

- The effectiveness of extinguishing powders is significantly higher than that of antiexplosion stone dust, whose operation is limited to physical mechanisms.

- The action of chemical inhibitors is not limited only to the reduction of the maximum explosion pressure $\mathrm{p}_{\max }$ and the maximum rate of explosion pressure rise $(\mathrm{dp} / \mathrm{dt})_{\max }$, there is also a modification of the course of explosion characteristics.

- The results of the tests obtained when spraying the inhibitor additives together with the wood dust samples do not allow to unambiguously state which of the extinguishing powders is more effective. Considering the nature of the effect of monoammonium phosphate on wood burning, a change in the way the inhibitor is introduced into the dust cloud could increase its observed efficacy.

- The test results correspond with the literature data on the effectiveness of individual inhibitors [6, 7]. Nevertheless, the differences in the range of minimal inerting concentrations indicates the need for further scientific research using other research methods, including studies in larger volumes and on a larger scale.

Issues related to explosive threats posed by pine dust and the possibility of limiting the effects of explosions with the use of inhibiting additives are very important. Determining the methods of testing the impact of various inhibitors on the course of explosion characteristics is the basis for further research in this field. Stand for testing the explosion characteristics of dust clouds according to PN-EN 14034 enables testing in the scope of effectiveness of inhibitors with different chemical composition, analysis of their impact on the course of explosion characteristics and determination of minimum inerting concentrations. One of the directions for further research using this position could be to determine the mathematical relationship between $\mathrm{p}_{\max }$ and $\mathrm{dp} / \mathrm{dt}_{\max }$ from the inhibitor concentration for different wood dust fractions.

\section{References}

1. K.L. Cashdolar, J. Loss. Prevent. Proc. 13, 183 (2000)

2. T. Abbasi, S.A. Abbasi, J. Hazard. Mater. 140, 7 (2007)

3. P.R. Amyotte, J. Loss. Prevent. Proc. 19, 161 (2006)

4. PN-EN 14034-1+A1:2011

5. S. Calle, L. Klaba, D. Thomas, L. Perrin, O. Dufaud, J. Loss. Prevent. Proc. 157, 144 (2005)

6. J. Amrogowicz, W. Kordylewski, Nauk. i Tech. Poż. 3, 42 (1998)

7. A. Dastidar, P. Amyotte, Trans. Am. Inst. Chem. Eng. 80 part B, 287 (2002) 